\title{
Jenny Shaw
}

Everyday Life in the Early English Caribbean: Irish, Africans, and the Construction of Difference. Athens: University of Georgia Press, 2014. Xv + 259 pp. (Paper Us\$24.95)

In her new book, historian Jenny Shaw offers a fresh look at the relationship between elites and nonelites, Whites and Blacks, and the English, Irish, and Africans in the early English Caribbean-Barbados in particular. Shaw is eager to demonstrate the parallel experiences of lowly Irish and enslaved Africans, both in the condition of their lives and the way they were viewed by English masters. More importantly, she sets out to turn the tables on much existing scholarship by describing how Irish and African subjects may have looked at each other, peered back at the English who sought to define and delineate their lives, and actively constructed an alternative world of "difference" in Barbados.

Shaw's task is a tricky one, but she calls on some useful allies to get it done. In order to try to make sense of the way Africans and the Irish may have seen things, she builds on the work (as her title indicates) of Michel de Certeau concerning the hidden meanings that can be teased out of everyday relationships and activities. Writing by Michel-Rolph Trouillot informs her effort to make use of the silences, or absences, that pervade the archives, where the records of the powerful and literate hold sway. She also tries to follow in the footsteps of Natalie Zemon Davis by making a virtue of her informed historical imagination where the absence of bountiful source materials might otherwise be viewed as a stumbling block. Her work is therefore not simply another study of the early English Caribbean but also a methodological treatise and an unapologetically creative act of historical intervention.

The separate chapters delineate discrete aspects of Shaw's larger argument about the extent to which "difference" was defined as much from below as it was from above. She begins with the familiar by noting how early colonial legislators strove to create categories that separated servants from slaves-Whites from Blacks-by using Christianity as the key legal signifier. The presence of Irish Catholics in places like Barbados, however, complicated matters considerably because of the disdain with which both Ireland and Catholicism were held in English society and culture. Thus, English elites needed to be a bit more creative. One way they did so, Shaw argues, was through enumeration methods in colonial censuses that allowed record keepers to transform, or hide, the Irish over time as they were either ignored as a distinct cohort or rolled into the emerging category of "White." In other words, Irish Catholics may have persisted as a distinct population in English islands, but they effectively disappeared from history as categories were manipulated for the sake of maintaining

(C) MiChaEl GUASCO, 2015 | DOI: 10.1163/22134360-08903033

This is an open access article distributed under the terms of the Creative Commons 
control over an ever-growing and troublesome population of non-English servants and, especially, enslaved Africans.

From this beginning, Shaw proceeds to consider the nonelite response. She argues that Irish servants and enslaved Africans had much in common: they were transported against their will, suffered ongoing abuses, endured rudimentary living conditions, and struggled to maintain their traditional religious structures in a hostile environment. Shaw's assertion that these shared circumstances promoted a kind of affinity—solidarity even — rests largely on the importance she places on proximity and the fears of English elites, some of which played out in violent acts of very real resistance in 1675 and 1692 . She construes 1692, in particular, as an effort on the part of Irish and African rebels not simply to break their shackles but to construct an alternate narrative of colonial formation in which ascribed meanings of race, culture, and religion were undone from below. Yet, even as the oppressed rallied together, Shaw notes that the more well-heeled Irish in the islands had already begun employing strategies to incorporate themselves into the English planter class by accumulating property, owning slaves, and minimizing their identity as Catholics.

Shaw successfully demonstrates that even as elites tried to manipulate societies, relationships, and identities, nonelites invariably pushed back. Her narrow gaze on what individual Irish Catholics, in particular, may have been thinking or doing is richly imaginative, but it is not always completely satisfying. She wants her elusive subjects to carry the narrative, but there is necessarily a great deal of educated guesswork in her enterprise. The larger context in which events transpired in the English islands also seems to get lost in the background haze, but that is less a flaw than it is a reminder that this is a book purposely and artfully crafted in shallow focus. Thus, if the big picture is hard to perceive in this study readers will still be enthralled by what Shaw wants them to see: how the Irish and Africans were not simply passive objects in the Caribbean, how they actively shaped their own lives, and how the seemingly inaccessible past can be made visible through creative research and the informed imagination.

\section{Michael Guasco}

Department of History, Davidson College, Davidson NC 28035, U.S.A. miguasco@davidson.edu 